\title{
Investigation of properties of rare earth complexes with dibromo-p-methyl-methylsulfonazo by spectral correction technique
}

\author{
HONG-WEN GAO ${ }^{\mathrm{a}}$, FA-SHUI HONG ${ }^{\mathrm{b}}$ and QING-SONG YE \\ ${ }^{a}$ School of Chemistry and Chemical Engineering, Anhui University, \\ Hefei 230039, P. R. China \\ ${ }^{\mathrm{b}}$ Department of Biological Science, Huaibei Coal Teachers College, \\ Huaibei 235000, P. R. China \\ e-mail: gaohongw@mail.hf.ah.cn
}

MS received 13 January 2000; revised 29 May 2000

\begin{abstract}
The reactions were sensitive between seven rare earth (RE) metals $\mathrm{Nd}(\mathrm{III}), \mathrm{La}(\mathrm{III}), \mathrm{Ce}(\mathrm{III}), \mathrm{Pr}(\mathrm{III}), \mathrm{Sm}(\mathrm{III}), \mathrm{Eu}(\mathrm{III})$ and $\mathrm{Gd}(\mathrm{III})$ and dibromo-p-methylmethylsulfonazo (DBMMSA) in acidic solution. The spectral correction method has been applied in the determination of properties of RE complexes instead of ordinary spectrophotometry. Composition ratios, real molar absorptivities $(\varepsilon)$ and stepwise stability constants $(K)$ of each of the RE complexes were determined easily because the method eliminated the absorption influence of excess of ligand on complex. Results showed that the cumulative $K$ values of the complexes were between $3.91 \times 10^{14}$ and $2.34 \times 10^{28}$ and the real (not apparent) absorptivity between $8.85 \times 10^{4}$ and $2 \cdot 12 \times 10^{5} 1 \mathrm{~mol}^{-1} \mathrm{~cm}^{-1}$ at $640 \mathrm{~nm}$.
\end{abstract}

Keywords. Spectral correction technique; rare earth; dibromo- $p$-methylmethylsulfonazo (DBMMSA).

\section{Introduction}

The synthesis of the ligand dibromo-p-methyl-methylsulfonazo (DBMMSA) was reported earlier ${ }^{1}$ and its structure is as given in chart 1 .<smiles>Cc1ccc(N=Nc2c(S(=O)(=O)O)cc3cc(S(=O)(=O)O)c(N=Nc4c(Br)cc(C)cc4S(=O)(=O)O)c(O)c3c2O)c(S(=O)(=O)O)c1</smiles>

Chart 1.

This reagent was earlier used in the determination of trace amounts of some metals ${ }^{2}$. However, the updated investigation showed that the free DBMMSA absorbs at the peak wavelength of the complex formed and so ordinary spectrophotometry may not work

*For correspondence 
with high precision and good accuracy. The new technique, the spectral correction method, is the first to eliminate the absorption influence of the excess of ligand and give the real absorption of the complex formed. It has been applied extensively in the determination of many complex solutions ${ }^{3-6}$. In the present report, the reactions between REs(III) and DBMMSA in acidic solution were studied in detail. Seven rare earth metals (Nd(III), $\mathrm{La}(\mathrm{III}), \mathrm{Ce}(\mathrm{III}), \mathrm{Pr}(\mathrm{III}), \mathrm{Sm}(\mathrm{III}), \mathrm{Eu}(\mathrm{III})$ and $\mathrm{Gd}(\mathrm{III})$ ) were observed to react sensitively with DBMMSA and to form blue complexes with composition ratios between 3 and 6. Determination of the real absorptivities $(K)$ and stepwise stability constants $(\varepsilon)$ of the complexes was also carried out. Results showed that the cumulative $K$ values of the complexes were between $3.91 \times 10^{14}$ and $2.34 \times 10^{28}$ and the real (not apparent) absorptivities were between $8.85 \times 10^{4}$ and $2.12 \times 10^{5} 1 \mathrm{~mol}^{-1} \mathrm{~cm}^{-1}$ at $640 \mathrm{~nm}$. The spectral correction technique was more acceptable in principle and simpler in operation than classical methods such as molar ratio $^{7}$, continuous variation ${ }^{8}$, equilibrium movement ${ }^{9}$ etc.

\section{Experimental}

\subsection{Apparatus and reagents}

Absorption spectra were recorded on a UV-VIS 265 spectrophotometer (Shimadzu, Japan) in $10 \mathrm{~mm}$ glass cells.

Standard Nd(III), $\mathrm{La}(\mathrm{IIII}), \mathrm{Ce}(\mathrm{III}), \mathrm{Pr}(\mathrm{III}), \mathrm{Sm}(\mathrm{III}), \mathrm{Eu}(\mathrm{III})$ and $\mathrm{Gd}(\mathrm{III})$ stock solutions, all $1.00 \mathrm{~g} / \mathrm{l}$ (oxide content) were provided by the National Geological Testing and Instrumentation Centre. Standard solutions of these, $0 \cdot 100 \mathrm{mmol} / 1$, were prepared by diluting the stock solutions with $0.32 \mathrm{mmol} / 1$ nitric acid. DBMMSA (purified and provided by Changke Reagent Institute of Shanghai, China) solution, $1.00 \mathrm{mmol} / \mathrm{l}$, was dissolved in non-ionic water and stored in a dark bottle. A solution of $5 \mathrm{~mol} / \mathrm{l}$ hydrochloric acid was prepared so as to adjust the optimum acidity of the complex solution. Non-ionic water with specific conductivity less than $0.3 \mu \mathrm{S} / \mathrm{cm}$ was prepared and used in this work.

\subsection{Recommended procedures}

RE (III) $0 \cdot 100 \mu \mathrm{mol}$ was taken in a $25 \mathrm{ml}$ volumetric flask. To this about $10 \mathrm{ml}$ distilled water was added, followed by $2 \mathrm{ml}$ of $5 \mathrm{~mol} / \mathrm{l}$ hydrochloric acid and $1.00 \mathrm{mmol} / \mathrm{l}$ DBMMSA. This was diluted to volume and mixed well. After $10 \mathrm{~min}$, the absorbances at 530 and $640 \mathrm{~nm}$ were measured against a reagent blank. The real absorbance $\left(A_{c}\right)$ of the complex was calculated according to the following expression,

$$
A_{c}=\frac{\Delta A-\beta \Delta A^{\prime}}{1-\alpha \beta}
$$

where

$$
\alpha=\frac{\varepsilon_{\mathrm{ML}_{\gamma}}^{\lambda_{1}}}{\varepsilon_{\mathrm{ML}_{\gamma}}^{\lambda_{2}}}=\frac{A_{\alpha}^{\prime}}{A_{\alpha}},
$$

and 


$$
\beta=\frac{\varepsilon_{L}^{\lambda_{2}}}{\varepsilon_{L}^{\lambda_{1}}}=\frac{A_{0}}{A_{0}^{\prime}} .
$$

Here, the terms $\Delta A$ and $\Delta A^{\prime}$ are absorbances of the reaction solution at $640\left(\lambda_{2}\right)$ and $530 \mathrm{~nm}\left(\lambda_{1}\right)$ against the reagent blank respectively. The coefficients, $\alpha$ and $\beta$ are the correction factors. The symbols, $\varepsilon_{\mathrm{ML} \gamma}{ }^{\lambda_{1}}, \varepsilon_{\mathrm{ML} \gamma}{ }^{\lambda_{2}}, \varepsilon_{L}^{{ }^{\lambda_{1}}}$ and $\varepsilon_{L}{ }^{\lambda_{2}}$ indicate the molar absorptivity of complex $\mathrm{ML}_{\gamma}$ and ligand (L) at 530 and $640 \mathrm{~nm}$ respectively.

In fact, the spectra correction method is also a dual-wavelength spectrophotometric method. However, it is different from the other conventional dual-wavelength methods ${ }^{10-14}$ in theory and operation.

\section{Results and discussion}

\subsection{Absorption spectra}

The absorption spectra of all rare earth metal (III) complexes with DBMMSA have the same or similar bending shapes but different absorptivities. In this section, $\mathrm{Nd}(\mathrm{III})$ was used as an example in the selection of the optimum operation conditions. Two wavelengths were selected such that the difference in absorbances was the maximum: 530 (valley absorption) and $640 \mathrm{~nm}$ (peak absorption). From the spectral curves, $\beta$ and $\alpha$ were calculated to be 0.132 and 0.422 respectively. The real absorption of RE-DBMMSA complex at $640 \mathrm{~nm}$ was calculated by the equation: $A_{c}=1.06\left(\Delta A-0 \cdot 132 \Delta A^{\prime}\right)$.

\subsection{Effect of addition of DBMMSA solution}

By varying the addition of $1.00 \mathrm{mmol} / \mathrm{l}$ DBMMSA, the absorption of the RE-DBMMSA reaction solution was measured. The effective fraction $(\eta \%)$ of DBMMSA and the complex ratio $\left(\gamma^{\prime}\right)$ of DBMMSA to RE were calculated according to the following equations.

$$
\gamma^{\prime}=\eta \times\left(C_{\mathrm{L}} / C_{\mathrm{M}}\right)
$$

where

$$
\eta=\left(A_{c}-\Delta A\right) / A_{0}
$$

The terms, $C_{\mathrm{M}}$ and $C_{\mathrm{L}}$ indicated the concentrations (mol/l) of RE and DBMMSA in the beginning respectively. $A_{0}{ }^{\prime}$ represented the absorption of the blank reagent at $530 \mathrm{~nm}$ against water. From their curves, the final RE complexes were expressed as follows: Nd(DBMMSA $)_{3}, \operatorname{La}(\text { DBMMSA })_{3}, \mathrm{Ce}(\text { DBMMSA })_{3}, \operatorname{Pr}(\text { DBMMSA })_{4}, \operatorname{Sm}(\text { DBMMSA })_{6}$, $\mathrm{Eu}(\mathrm{DBMMSA})_{4}$ and Gd(DBMMSA $)_{4}$. The combined and free DBMMSA in their RE reaction solutions were shown in table 1 where the complex ratio approached or reached the final constant 2. We observed that the excess of DBMMSA took up about $80 \%$ of the total addition of DBMMSA in $\mathrm{Nd}$ (III) solution, $71 \%$ in $\mathrm{La}(\mathrm{III})$ solution, $71 \%$ in $\mathrm{Ce}$ (III) solution, $74 \%$ in $\mathrm{Pr}(\mathrm{III})$ solution, $75 \%$ in $\mathrm{Sm}$ (III) solution, $85 \%$ in $\mathrm{Eu}$ (III) solution and $87 \%$ in Gd(III) solution respectively. Therefore, over $70 \%$ of the total addition of DBMMSA did not join the combination with RE. Undoubtedly, such high DBMMSAfree concentration did affect the measurement of real absorption of RE-DBMMSA complexes. 
Table 1. The effective percentage and the excess of DBMMSA in its RE solutions when the complexation ratio of DBMMSA to RE approaches the maximum.

\begin{tabular}{lccc}
\hline $\begin{array}{l}\text { RE addition } \\
(\mu \mathrm{g} / 25 \mathrm{ml})\end{array}$ & $\begin{array}{c}\text { Minimum addition } \\
\text { of DBMMSA }(\mu \mathrm{mol} / 25 \mathrm{ml})\end{array}$ & $\begin{array}{c}\text { Combination of } \\
\text { DBMMSA }(\eta \%)\end{array}$ & $\begin{array}{c}\text { Excess of DBMMSA } \\
(\%)\end{array}$ \\
\hline $\mathrm{Nd}(\mathrm{III}) 0 \cdot 100$ & $1 \cdot 50$ & 20 & 80 \\
$\mathrm{La}(\mathrm{III}) 0 \cdot 100$ & $1 \cdot 00$ & 29 & 71 \\
$\mathrm{Ce}(\mathrm{III}) 0 \cdot 100$ & $1 \cdot 00$ & 29 & 71 \\
$\mathrm{Pr}(\mathrm{III}) 0 \cdot 100$ & $1 \cdot 50$ & 26 & 74 \\
$\mathrm{Sm}$ (III) $0 \cdot 100$ & $2 \cdot 00$ & 25 & 75 \\
$\mathrm{Eu}(\mathrm{III}) 0 \cdot 100$ & $2 \cdot 50$ & 15 & 85 \\
$\mathrm{Gd}(\mathrm{III}) 0 \cdot 100$ & $3 \cdot 00$ & 13 & 87 \\
\hline
\end{tabular}

\subsection{Effect of $\mathrm{pH}$ and reaction time}

By varying the acidity of the solution, the absorption of the Nd-DBMMSA solution was measured. We observed that the sensitivity of the RE-DBMMSA reaction reached the maximum in acidic solution. Therefore, all determinations were made in acidic solution. The effect of reaction time on the real absorption of Nd-DBMMSA complex showed that the reaction between RE and DBMMSA was complete in 10 minutes.

\subsection{Determination of stability constant and real absorptivity of complex}

The stepwise stability constant $\left(K_{n}\right)$, cumulative stability constant $(K)$ and stepwise absorptivity $(\varepsilon)$ of the complex can be calculated from the following equations:

$$
K_{n}=\frac{\gamma^{\prime}+1-n}{\left(n-\gamma^{\prime}\right)\left(C_{\mathrm{L}}-\gamma^{\prime} C_{\mathrm{M}}\right)},
$$

and

$$
\varepsilon_{\mathrm{ML}_{n}}^{\lambda_{2}}=\frac{A_{c}}{\delta C_{\mathrm{M}}\left(\gamma^{\prime}+1-n\right)}-\frac{n-\gamma^{\prime}}{\gamma^{\prime}+1-n} \varepsilon_{\mathrm{ML}_{n-1}}^{\lambda_{2}}
$$

Here, the symbols, $n$ indicates the $n$th complex and $\delta$ the thickness of the cell. The complex ratio $\gamma^{\prime}$ must be kept between $n-1$ and $n$ by preparing a mixed solution. The following solutions were prepared for the determination of the stepwise stability constants and the stepwise real absorptivities of RE-DBMMSA complexes: $0 \cdot 100 \mu \mathrm{mol}$ of $\mathrm{Nd}(\mathrm{III})$ with $0.300,0.600$ and $0.800 \mu \mathrm{mol}$ of DBMMSA, $0 \cdot 100 \mu \mathrm{mol}$ of $\mathrm{La}(\mathrm{III})$ with $0.300,0.400$ and $0.600 \mu \mathrm{mol}$ of DBMMSA, $0.100 \mu \mathrm{g}$ of Ce(III) with $0.300,0.400$ and $0.800 \mu \mathrm{mol}$ of DBMMSA, $0 \cdot 100 \mu \mathrm{g}$ of $\operatorname{Pr}(\mathrm{III})$ with $0.300,0.500,0.700$ and $1.00 \mu \mathrm{mol}$ of DBMMSA, $0 \cdot 100 \mu \mathrm{g}$ of Sm(III) with $0.300,0.500,0.800,1.00,1.25$ and $2.00 \mu \mathrm{mol}$ of DBMMSA, $0 \cdot 100 \mu \mathrm{g}$ of Eu(III) with $0 \cdot 500,0 \cdot 800,1 \cdot 25$ and $2 \cdot 00 \mu \mathrm{mol}$ of DBMMSA and $0 \cdot 100 \mu \mathrm{g}$ of $\mathrm{Gd}(\mathrm{III})$ with $0 \cdot 800,1 \cdot 25,1.50$ and $2.50 \mu \mathrm{mol}$ of DBMMSA. Three replicated 
Table 2. The determination of the stepwise stability constant and the stepwise real absorptivity of all RE (DBMMSA) ${ }_{n}$ at ionic strength $0 \cdot 1$ and temperature $12^{\circ} \mathrm{C}$.

\begin{tabular}{|c|c|c|c|c|}
\hline \multirow[b]{2}{*}{$\mathrm{M}-\mathrm{L}$ reaction } & \multicolumn{4}{|c|}{ Stepwise stability constant } \\
\hline & $K_{3}$ & $K_{4}$ & $K_{5}$ & $K_{6}$ \\
\hline Nd-BMMSA & $(2.64 \pm 0.29) \times 10^{4}$ & & & \\
\hline La-DBMMSA & $(6.80 \pm 0.54) \times 10^{4}$ & & & \\
\hline Ce-DBMMSA & $(1.03 \pm 0.15) \times 10^{5}$ & & & \\
\hline Pr-DBMMSA & $(1 \cdot 10 \pm 0.08) \times 10^{5}$ & $(3.77 \pm 0.66) \times 10^{4}$ & & \\
\hline Sm-BMMSA & $(9.39 \pm 1.41) \times 10^{4}$ & $(8.69 \pm 1.22) \times 10^{4}$ & $(2 \cdot 44 \pm 0.38) \times$ & $1 \pm 0 \cdot 19) \times 10^{4}$ \\
\hline Eu-DBMMSA & $(3.63 \pm 0.26) \times 10^{4}$ & $(1.40 \pm 0.18) \times 10^{4}$ & & \\
\hline \multirow[t]{3}{*}{ Gd-DBMMSA } & $(8 \cdot 77 \pm 1 \cdot 12) \times 10^{3}$ & $(7 \cdot 04 \pm 0.98) \times 10^{3}$ & & \\
\hline & \multicolumn{4}{|c|}{ Stepwise absorptivity at $640 \mathrm{~nm}, 1 \mathrm{~mol}^{-1} \mathrm{~cm}^{-1}$} \\
\hline & $\varepsilon_{\mathrm{ML} 3}$ & $\varepsilon_{\mathrm{ML} 4}$ & $\varepsilon_{\mathrm{ML} 5}$ & $\varepsilon_{\mathrm{ML} 6}$ \\
\hline Nd-DBMMSA & $8 \cdot 85 \times 10^{4}$ & & & \\
\hline La-DBMMSA & $9.44 \times 10^{4}$ & & & \\
\hline Ce-DBMMSA & $1 \cdot 10 \times 10^{5}$ & & & \\
\hline Pr-DBMMSA & $9.78 \times 10^{4}$ & $1.29 \times 10^{5}$ & & \\
\hline Sm-DBMMSA & $9.77 \times 10^{4}$ & $1.33 \times 10^{5}$ & $1.63 \times 10^{5}$ & $2 \cdot 12 \times 10^{5}$ \\
\hline Eu-DBMMSA & $8.74 \times 10^{4}$ & $1.57 \times 10^{5}$ & & \\
\hline Gd-DBMMSA & $8.62 \times 10^{4}$ & $1.38 \times 10^{5}$ & & \\
\hline
\end{tabular}

preparations and determinations of each were carried out and results are shown in table 2 . Standard deviations of $K \mathrm{~s}$ are listed, which are less than $20 \%$ of the average. The cumulative stability constant $(K)$ of $\operatorname{RE}(\mathrm{DBMMSA})_{n}$ was followed: $\mathrm{Nd}(\mathrm{DBMMSA})_{3}$ $3.91 \times 10^{14}, \mathrm{La}(\text { DBMMSA })_{3} 3.93 \times 10^{14}, \mathrm{Ce}(\text { DBMMSA })_{3} 2.85 \times 10^{15}, \operatorname{Pr}(\text { DBMMSA })_{4}$ $3.47 \times 10^{19}, \quad$ Sm(DBMMSA) $6 \quad 2.34 \times 10^{28}, \quad$ Eu(DBMMSA $)_{4} \quad 9.73 \times 10^{17}$ and $\operatorname{Gd}(\mathrm{DBMMSA})_{4} 4.42 \times 10^{17}$ respectively. All these reactions were determined at ionic strength $0.1 \mathrm{~mol} / \mathrm{l}$ and at a temperature of $12^{\circ} \mathrm{C}$. We observed that the cumulative stability constants of complexes increased with the increase of the final complex ratio. The stepwise real absorptivities, $\varepsilon_{\mathrm{ML}}^{\lambda_{2}}$ of RE(DBMMSA) ${ }_{n}$ were all between $8.85 \times 10^{4}$ and $2.12 \times 10^{5} 1 \mathrm{~mol}^{-1} \mathrm{~cm}^{-1}$ at $640 \mathrm{~nm}^{n}$ (table 2). The greater the complex ratios of RE to DBMMSA, the greater were the absorptivities of the complex. In any rare earth complex, the absorptivity of the next-step complex is always more than that of the last-step complex because the increase of ligand in complex composition enhances the absorption of the complex solution. By contrast, the same step RE complex had similar real absorptivity, for example all RE(DBMMSA) had values between $3 \cdot 20$ and $3.81 \times 10^{4} 1 \mathrm{~mol}^{-1} \mathrm{~cm}^{-1}$ at $640 \mathrm{~nm}$ (except the Nd complex), all RE(DBMMSA) $)_{2}$ were between 6.13 and $7.60 \times 10^{4} 1 \mathrm{~mol}^{-1} \mathrm{~cm}^{-1}$ at $640 \mathrm{~nm}$ (except the $\mathrm{Gd}$ complex) and all $\operatorname{RE}(\text { DBMMSA })_{3}$ were between 8.62 and $11.0 \times 10^{4} 1 \mathrm{~mol}^{-1} \mathrm{~cm}^{-1}$ at $640 \mathrm{~nm}$. 


\section{Acknowledgement}

This work was supported by the Natural Science Foundation of the Anhui Province (No. 99045332) and by the Education Commission of the Anhui Province (99JL0003).

\section{References}

1. Pan J M and Xu Z J 1996 Huaxue Shiji. 1865

2. Pan J M, Liu R and Xu Z J 1997 Fenxi Kexue Xuebao 13142

3. Gao H W 1995 Spectrochim. Acta A51 1379

4. Gao H W and Zhang P F 1998 Zav. Lab. 654

5. Gao H W and Zhang P F 1994 Analyst 1192109

6. Gao H W 1999 Asian J. Chem. 11319

7. Tikhonov V N 1975 Zh. Anal. Khim. 301501

8. Likussar W 1973 Anal. Chem. 451926

9. Laearev A I 1975 Zavod. Lab. 41534

10. Watanabe H and Ohmori H 1979 Talanta 26959

11. Chen D 1989 Anal. Chim. Acta 222205

12. Ratzlaff K L 1977 Anal. Chem. 492170

13. Gao H W 1999 J. Anal. Chem. 54941

14. Wei J S 1985 Fenxi Huaxue 13762 